\title{
Pre-gestational excessive weight and duration of breast-feeding
}

\author{
Andréa M Sotero ${ }^{1, *}$, Haroldo da S Ferreira ${ }^{2}$, Monica L Assunção ${ }^{3}$ and Pedro Israel C de Lira ${ }^{4}$ \\ ${ }^{1}$ Collegiate of Nutrition, University of Pernambuco, BR 203, Km2, s/n, University Campus, Vila Eduardo, Petrolina, \\ Pernambuco, CEP 46.328-903, Brazil: ${ }^{2}$ Postgraduate Program in Nutrition, Faculty of Nutrition, Federal University \\ of Alagoas, Maceió, Alagoas, Brazil: ${ }^{3}$ Faculty of Nutrition, Federal University of Alagoas, Maceió, Alagoas, Brazil: \\ ${ }^{4}$ Postgraduate Program in Nutrition, University of Pernambuco, Recife, Pernambuco, Brazil
}

Submitted 23 March 2017: Final revision received 28 July 2017: Accepted 14 August 2017: First published online 13 October 2017

\begin{abstract}
Objective: To investigate whether pre-gestational obesity interferes with the duration of breast-feeding.

Design: A cross-sectional study was carried out with a population-based probabilistic sample. The dependent variables were exclusive breast-feeding (EBF) and breast-feeding (BF), as defined by the WHO. The classification of pre-gestational nutritional status was based on the pre-gestational BMI category. Subjects: A sample of 418 mother-infant pairs from the state of Alagoas, Brazil. Results: The median duration of EBF was 1.9 months $(60 \mathrm{~d})$, while that of BF was 8.2 months $(250 \mathrm{~d})$. According to multiple linear regression analysis, the factors that negatively and independently affected the duration of EBF were pregestational $\mathrm{BMI} \geq 30 \cdot 0 \mathrm{~kg} / \mathrm{m}^{2}(-51.9 \mathrm{~d}, 95 \% \mathrm{CI}-80 \cdot 4,-23 \cdot 4)$, maternal schooling $\leq 9$ years $(-30 \cdot 8 \mathrm{~d}, 95 \% \mathrm{CI}-54 \cdot 7,-6 \cdot 9)$, no prior lactation experience $(-29 \cdot 0 \mathrm{~d}$, $95 \% \mathrm{CI}-45 \cdot 6,-11 \cdot 5)$ and infant pacifier use $(-41 \cdot 4 \mathrm{~d} ; 95 \%$ CI $54 \cdot 5,-28 \cdot 2)$. For BF, a higher weaning rate was observed during the first days after birth among children of pre-gestational obese mothers.

Conclusions: The results suggest that higher pre-gestational BMI is associated with shorter duration of EBF and BF. Prenatal care provides a privileged opportunity to promote nutritional education, better nutritional status of pregnant woman, and greater success with EBF up to 6 months of age and with longer BF.
\end{abstract}

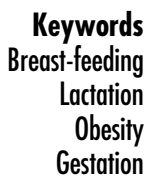

Considered one of the main public health problems worldwide, obesity is a disease that affects individuals in different economic classes and age groups. Among women of reproductive age, the prevalence of obesity is approximately $25 \%$ in Brazil, some European countries and the USA ${ }^{(1-4)}$.

Obesity during the pre-conception period tends to persist or worsen during the pregnancy-puerperal cycle, resulting in increased obstetric risks (congenital malformation, gestational diabetes, hypertension, thromboembolism) and continuity of complications during childbirth (premature delivery, dystocia), puerperium and lactation. Regarding lactation, a growing number of publications have demonstrated greater difficulties in initiating and maintaining the practice of breast-feeding among women who are obese during the pre-gestational period ${ }^{(5-8)}$.

The association between low lactational performance and high pre-gestational BMI may be due to several causes. These include alterations related to the biological sphere, such as modification of the mammary anatomy; adverse clinical conditions caused by overweight that promote separation of mother and child after birth; psychological factors, such as higher rates of postpartum depression; and physiological causes, such as delayed lactogenesis II due to a lower prolactin response in the first $72 \mathrm{~h}$ of the puerperium period ${ }^{(9)}$.

Impaired lactation performance predisposes infants to a higher risk of developing both short- and long-term morbid conditions, such as intestinal infections, respiratory infections, allergies, obesity and type 2 diabetes ${ }^{(4)}$.

On the other hand, recent studies have demonstrated a dose-dependent association between the duration of breast-feeding and decreased risk of obesity in children $^{(10,11)}$, a problem that has become of increasing concern to society, health professionals and policy makers.

The Brazilian state of Alagoas exhibits the worst economic and social indicators in the country ${ }^{(12)}$. Its population has the lowest average income, the highest proportion of people classified below the poverty line and the lowest educational levels. In addition, the state has evolved economically at a slower rate than other Brazilian states $^{(13)}$. Thus, public health in Alagoas in particular could be positively affected by a wider and more effective practice of exclusive breast-feeding. 
Changes in the pattern of nutritional problems have resulted in increased obesity in younger age groups. With the aim of preventing those problems through breast-feeding, the present study evaluated whether pregestational obesity reduces the duration of breast-feeding in a Brazilian Northeast state.

\section{Materials and methods}

The present study was a cross-sectional analysis that utilized the II Diagnosis of Health of Maternal and Child Population of Alagoas State survey, which evaluated 418 children up to 24 months of age and their respective mothers.

To compose the sample, a multiple-stage process was adopted with four stages. In the first stage, twenty municipalities were randomly selected through systematic sampling with a probability proportional to size. For this, the municipalities were organized in alphabetical order according to their respective geographic regions and population sizes. In the second stage, four census tracts were drawn in each municipality with consideration of the proportion between urban and rural sectors. In the third stage, a block was drawn within each census section. In the fourth and final stage, a starting point was drawn within each block and twenty-eight consecutive households were visited.

\section{Inclusion and exclusion criteria}

All children under 24 months of age residing in households that were randomly selected were eligible for the study.

Children and/or mothers who presented pathologies at birth that impeded breast-feeding were excluded from the study. These conditions included mothers with HIV and children with a cleft lip. This information was obtained through a questionnaire administered to the biological mother. Thus, being an adoptive mother was an exclusion criterion since breast-feeding under such circumstances is less likely to occur.

\section{Data collection}

The fieldwork was carried out between January 2014 and January 2015 by a team of trained and supervised interviewers.

The data were collected through home visits using structured questionnaires that were pre-tested in a pilot study. Data on socio-economic and demographic characteristics, access to public services, the mothers and children, and breast-feeding and infant feeding were collected.

\section{Definition of study variables}

\section{Dependent variables}

The dependent variables were exclusive breast-feeding (EBF) and breast-feeding (BF), which were defined according to the definitions proposed by the $\mathrm{WHO}^{(14)}$.
The WHO considers children to be exclusively breast-fed if they receive only breast milk direct from the breast, expressed milk from the mother, or human milk from other sources without other liquids or solids, except for drops or syrups containing vitamins, oral rehydration salts, mineral supplements or medicinal products. The BF period refers to the maximum period during which the child receives breast milk (directly from the breast or expressed milk) regardless of whether he/she receives other foods.

The data collection instrument consisted of a direct question regarding the amount of time that the child was exclusively breast-fed. In addition, questions about the age of introduction of water, tea, milk from sources other than the mother, or any other foods were included to complement the responses regarding the duration of $\mathrm{EBF}$, thus increasing the consistency of the obtained information.

\section{Independent variables}

To characterize the sample, the following variables were used: maternal schooling (years of full study by the mother were categorized into primary school ( $\leq 4$ years of schooling), high school (5-9 years of schooling) and higher education ( $\geq 10$ years of schooling)), family income per capita according to the minimum wage (computed as the sum of the incomes of all family members residing in the same household in the month prior to the interview), number of prenatal consultations, previous breast-feeding experience, pregnancy complications, use of cigarettes during pregnancy, suckling in the first hour after birth, birth weight and use of pacifiers by the infant.

Maternal nutritional status was assessed by calculating the pre-gestational BMI, which referred to the mother's typical weight before pregnancy. Subsequently, pregestational BMI was categorized according to the criteria adopted by the Institute of Medicine ${ }^{(15)}$ : low maternal weight $\left(\mathrm{BMI}<18.5 \mathrm{~kg} / \mathrm{m}^{2}\right)$, normal weight $(\mathrm{BMI}=18.5-$ $\left.24.9 \mathrm{~kg} / \mathrm{m}^{2}\right)$, overweight $\left(\mathrm{BMI}=25.0-29.9 \mathrm{~kg} / \mathrm{m}^{2}\right)$ and obesity (BMI $\left.\geq 30 \cdot 0 \mathrm{~kg} / \mathrm{m}^{2}\right)$.

The data were typed into a double-entry form and processed using Epi-info software version 3.5.1. Statistical analysis was performed using PASW Statistics version 18.0. To analyse the median duration of breast-feeding practices, survival curves were constructed using the life table method, representing the cumulative probability of breastfeeding over the months. Children who were breast-fed for at least $30 \mathrm{~d}$ by mothers spanning the four categories of pre-gestational BMI were considered. Children whose mothers reported not breast-feeding were included in the survival analysis as having breast-fed for $1 \mathrm{~d}$. The duration of breast-feeding was assessed retrospectively at 7 and 24 months for EBF and BF, respectively. The association between the independent variables and the duration of breast-feeding was estimated by the Wilcoxon test.

The variables that obtained $P<0.20$ among the infants who completed $\mathrm{EBF}$ ( $n$ 381) were entered in the final multiple linear regression model. The basal category for the estimation 
of the adjusted $\beta$ value was defined as the one with the lowest risk of compromising the duration of breast-feeding', i.e. mothers whose nutritional status was normal weight.

The Human Research Ethics Committee of the Federal University of Alagoas approved the study under protocol number 09093012.0.0000.5013. The research objectives and the reliability of the data were explained to the families, and they signed the informed consent form prior to the interviews.

\section{Results}

A total of 418 mother-infant dyads were evaluated. The mean age of the mothers and children was 28 (SD 7) years and 15 (SD 6) months, respectively. There was an equal distribution of boys and girls. The mean pre-pregnancy BMI was 23.4 (sD 4.7$) \mathrm{kg} / \mathrm{m}^{2}$.

The median duration of EBF was 1.9 months $(60 \mathrm{~d})$, while that of $\mathrm{BF}$ was 8.2 months $(250 \mathrm{~d})$. Among the children analysed, twenty-nine (6\%) never breast-fed, 214 (45\%) were still breast-feeding and $174(36 \%)$ had already been weaned. Among children younger than 6 months ( $n$ 106), the prevalence of EBF was $84.2 \%$ (Fig. 1).

Regarding the nutritional classifications (pre-gestational BMI), $56 \cdot 2 \%$ of the mothers were normal weight, while $31.6 \%$ had excess weight $(21.3 \%$ were overweight and $10.3 \%$ were obese). It was observed that $98.6 \%$ of the mothers underwent prenatal care; of these mothers, $78.9 \%$ had six or more visits, as recommended by the Ministry of Health. Among mothers who had previous experience with breast-feeding, $53.4 \%$ were multiparous and $26.6 \%$ were primiparous. Among the children, 5.7\% were born with a low birth weight and $50 \cdot 1 \%$ had used pacifiers (Table 1).

When comparing the survival curves relative to the different breast-feeding practices (Figs 2 and 3) according to the pre-gestational BMI categories, EBF soon after birth was not a universal practice among the children of obese mothers. At the end of the second month of life, only $48 \%$ of the children received breast milk exclusively. In the following months, there was a systematic decline such that by the end of the fourth month, only $24 \%$ of these children were being exclusively breast-fed, and only $4 \%$ obtained this status at the sixth month of life.

For BF, babies of obese mothers were less often breastfed at ages 2-12 months, but from 18-24 months, this was instead true for the babies of the overweight mothers. However, none of these differences were tested for statistical significance.

According to the survival analysis, the duration of breastfeeding practices was significantly higher among the pregestational normal-weight mothers than among those with pre-gestational obesity: EBF (2.8v. 2.3 months, $P=0.045)$ and $\mathrm{BF}(15.5 v .6 .7$ months, $P<0.001)$. Mothers who had six or more prenatal consultations had higher medians for both breast-feeding practices, although the difference was not statistically significant. Mothers who had previous breast-feeding experience and the mothers who had not previously breast-fed because they were primiparous contributed to the significantly higher median durations of EBF (3.3 months) and BF (14.5 months) among women with previous breast-feeding experience compared with those without previous breast-feeding experience: EBF (1.8 months, $P<0.01)$ and $\mathrm{BF}(11.3$ months, $P=0.023)$. Among children, the use of pacifiers was negatively associated with the duration of EBF when compared with the lack of use $(2 \cdot 2 v \cdot 3 \cdot 8$ months, $P<0 \cdot 001)$.

Table 2 shows the results obtained from the multiple linear regression analysis of factors associated with the duration of EBF among the children who completed EBF ( $n$ 381). The factors that negatively and independently affected the duration of EBF were pre-gestational

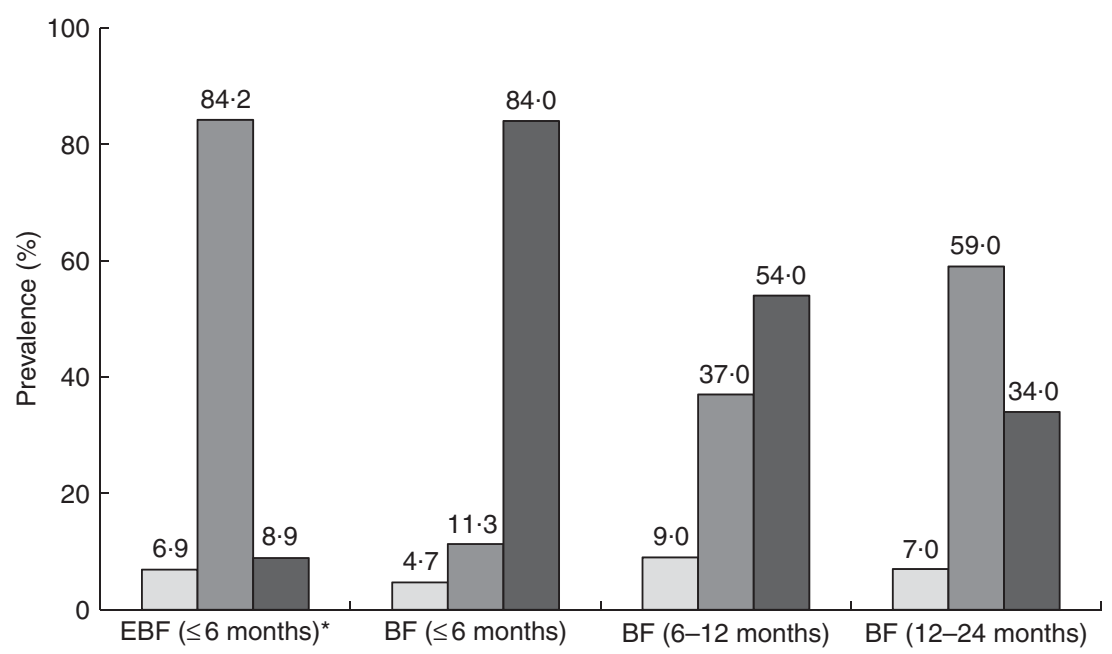

Fig. 1 Practice of exclusive breast-feeding (EBF) and breast-feeding (BF) of infants ( $\square$, never breast-fed; $\square$, breast-fed; $\square$, still breast-feeding) by age group (months), Alagoas, Brazil, 2015. *Including twenty-three (5.5\%) infants (>6 and $\leq 7$ months of age) who were exclusively breast-fed 
Table 1 Associations of the duration of exclusive breast-feeding (EBF) and breast-feeding (BF) with explanatory variables, Alagoas, Brazil, 2015

\begin{tabular}{|c|c|c|c|c|c|c|}
\hline \multirow[b]{2}{*}{ Variable } & \multicolumn{2}{|c|}{ Total $(n 418)$} & \multicolumn{2}{|c|}{ EBF (months) } & \multicolumn{2}{|c|}{ BF (months) } \\
\hline & $n$ & $\%$ & Median & $P^{*}$ & Median & $P^{*}$ \\
\hline \multicolumn{7}{|l|}{ Pre-gestational BMI $\left(\mathrm{kg} / \mathrm{m}^{2}\right)$} \\
\hline$<18.5$ & 51 & $12 \cdot 2$ & 4.1 & \multirow[t]{4}{*}{0.045} & 17.5 & \multirow[t]{4}{*}{$<0.001$} \\
\hline $18 \cdot 5-24.9$ & 235 & $56 \cdot 2$ & $2 \cdot 8$ & & $15 \cdot 5$ & \\
\hline $25 \cdot 0-29.9$ & 89 & 21.3 & $2 \cdot 8$ & & $12 \cdot 1$ & \\
\hline$\geq 30 \cdot 0$ & 43 & $10 \cdot 3$ & $2 \cdot 3$ & & $6 \cdot 7$ & \\
\hline \multicolumn{7}{|l|}{ Maternal education $\dagger$} \\
\hline Primary school ( $\leq 4$ years) & 198 & $50 \cdot 8$ & 2.5 & \multirow[t]{3}{*}{0.065} & 14.4 & \multirow[t]{3}{*}{0.527} \\
\hline High school (5-9 years) & 155 & $39 \cdot 7$ & 3.4 & & $15 \cdot 4$ & \\
\hline Higher education ( $>10$ years) & 37 & 9.5 & 4.1 & & 11.3 & \\
\hline \multicolumn{7}{|c|}{ Income per capita (minimum wages) $\ddagger$} \\
\hline$<1$ & 116 & $30 \cdot 4$ & 3.0 & \multirow[t]{3}{*}{0.916} & $12 \cdot 5$ & \multirow[t]{3}{*}{0.235} \\
\hline $1-2$ & 152 & $39 \cdot 9$ & $2 \cdot 8$ & & $16 \cdot 1$ & \\
\hline$>2$ & 113 & $29 \cdot 6$ & 3.0 & & 14.9 & \\
\hline \multicolumn{7}{|l|}{ Prenatal consultation§ } \\
\hline$<6$ & 87 & $21 \cdot 1$ & $2 \cdot 6$ & \multirow[t]{2}{*}{0.325} & $12 \cdot 3$ & \multirow[t]{2}{*}{0.406} \\
\hline$>6$ & 325 & 78.9 & 3.0 & & 14.7 & \\
\hline \multicolumn{7}{|c|}{ Previous breast-feeding experience } \\
\hline Yes & 214 & 53.4 & $3 \cdot 3$ & \multirow[t]{3}{*}{0.01} & 14.5 & \multirow[t]{3}{*}{0.023} \\
\hline No & 80 & $20 \cdot 0$ & 1.8 & & 11.3 & \\
\hline Never (primiparous) & 107 & $26 \cdot 6$ & 3.2 & & $15 \cdot 5$ & \\
\hline \multicolumn{7}{|l|}{ Weight at birth $(\mathrm{g}) \boldsymbol{I}$} \\
\hline$<2500$ & 23 & $5 \cdot 7$ & 3.0 & \multirow[t]{3}{*}{0.378} & $20 \cdot 2$ & \multirow[t]{3}{*}{0.305} \\
\hline $2500-2999$ & 79 & $19 \cdot 5$ & 2.6 & & $15 \cdot 6$ & \\
\hline$>2999$ & 304 & 74.8 & $3 \cdot 1$ & & 9.9 & \\
\hline \multicolumn{7}{|l|}{ Breast-fed in the first hour ${ }^{\star *}$} \\
\hline Yes & 276 & $66 \cdot 8$ & $3 \cdot 2$ & \multirow[t]{2}{*}{0.084} & $14 \cdot 8$ & \multirow[t]{2}{*}{0.992} \\
\hline No & 137 & 33.2 & 2.5 & & $14 \cdot 3$ & \\
\hline \multicolumn{7}{|l|}{ Complications in pregnancy†† } \\
\hline Yes & 163 & 39.1 & 3.0 & \multirow[t]{2}{*}{0.772} & 13.9 & 0.090 \\
\hline No & 254 & $60 \cdot 9$ & 2.9 & & $15 \cdot 2$ & \\
\hline Smoking during pregnancy & & & & & & \\
\hline Yes & 21 & $5 \cdot 0$ & 1.9 & 0.193 & 13.5 & 0.436 \\
\hline No & 397 & $95 \cdot 0$ & $3 \cdot 1$ & & $15 \cdot 0$ & \\
\hline Pacifier use & & & & & & \\
\hline Yes & 205 & $50 \cdot 1$ & $2 \cdot 2$ & $<0.001$ & $15 \cdot 5$ & 0.104 \\
\hline No & 204 & $49 \cdot 8$ & 3.8 & & $12 \cdot 7$ & \\
\hline
\end{tabular}

Minimum wage at the time of the survey was $\mathrm{R} \$ 724.00$

*Wilcoxon's test.

†Twenty-eight cases without information.

$\ddagger$ Thirty-seven cases without information.

$\S$ Six cases without information.

Seventeen cases without information.

ITTwelve cases without information.

${ }^{\star *}$ Five cases without information.

††One case without information.

$\ddagger \ddagger N i n e$ cases without information.

$\mathrm{BMI} \geq 30 \cdot 0 \mathrm{~kg} / \mathrm{m}^{2} \quad(-51.9 \mathrm{~d}, \quad 95 \% \quad$ CI $\quad-80.4, \quad-23.4 \mathrm{~d}$; $P=0.002)$, maternal schooling $\leq 9$ years $(-30.8 \mathrm{~d}, 95 \% \mathrm{CI}$ $-54.7,-6.9 \mathrm{~d} ; P=0.035)$, no prior lactation experience $(-29.0 \mathrm{~d}, 95 \% \mathrm{CI}-45.6,-11.5 \mathrm{~d} ; P=0.002)$ and infant pacifier use $(-41.4 \mathrm{~d}, 95 \% \mathrm{CI}-54.5,-28 \cdot 2 \mathrm{~d} ; P<0.001)$.

\section{Discussion}

The results of our sample point to a higher proportion of various breast-feeding practices in Alagoas than cited in other studies in the literature ${ }^{(12,16)}$. For example, in the National Survey of Demography and Children's and Women's Health (PNDS) ${ }^{(17)}$, the percentage was $39.8 \%$, and the Prevalence of Breastfeeding in the Brazilian
Capitals and Federal District (PPAM/Capitals and DF) ${ }^{(18)}$ survey reported a prevalence of $41 \%$ in the Brazilian capitals and $37 \%$ in the Northeast; while in the present study a proportion of maternal breast-feeding among children up to 6 months of $84 \cdot 2 \%$ was observed. The great discrepancy between these values may be due to the temporal difference between the studies in the literature, which occurred between the years of 2006 and 2008, and the present research which was conducted in 2015. These and other results in the literature are far below the desired level, as the great majority of children up to 6 months of age should be exclusively breast-fed.

Among children aged 12 months or older, a lower prevalence was observed in the current study than in the studies mentioned above ${ }^{(17,18)}$. In the literature, there are 


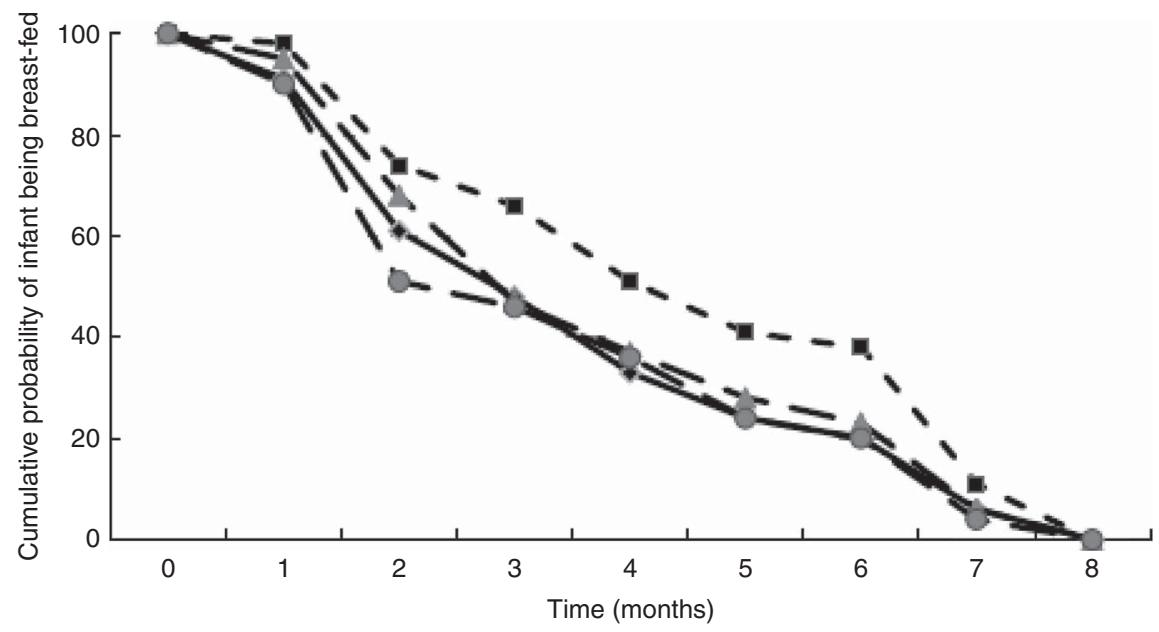

Fig. 2 Exclusive breast-feeding practice* of infants according to pre-gestational BMI† (- - -, low weight; $-\bullet-$, normal weight; $-\rightarrow-$, overweight; $-O-$, obesity), Alagoas, Brazil, 2015. *Wilcoxon's test: $P=0.045$. †Low weight, BMl $<18.5 \mathrm{~kg} / \mathrm{m}^{2} ;$ normal weight, $\mathrm{BMI}=18.5-24.9 \mathrm{~kg} / \mathrm{m}^{2}$; overweight, $\mathrm{BMI}=25.0-29.9 \mathrm{~kg} / \mathrm{m}^{2} ;$ obesity, $\mathrm{BMI} \geq 30.0 \mathrm{~kg} / \mathrm{m}^{2}$

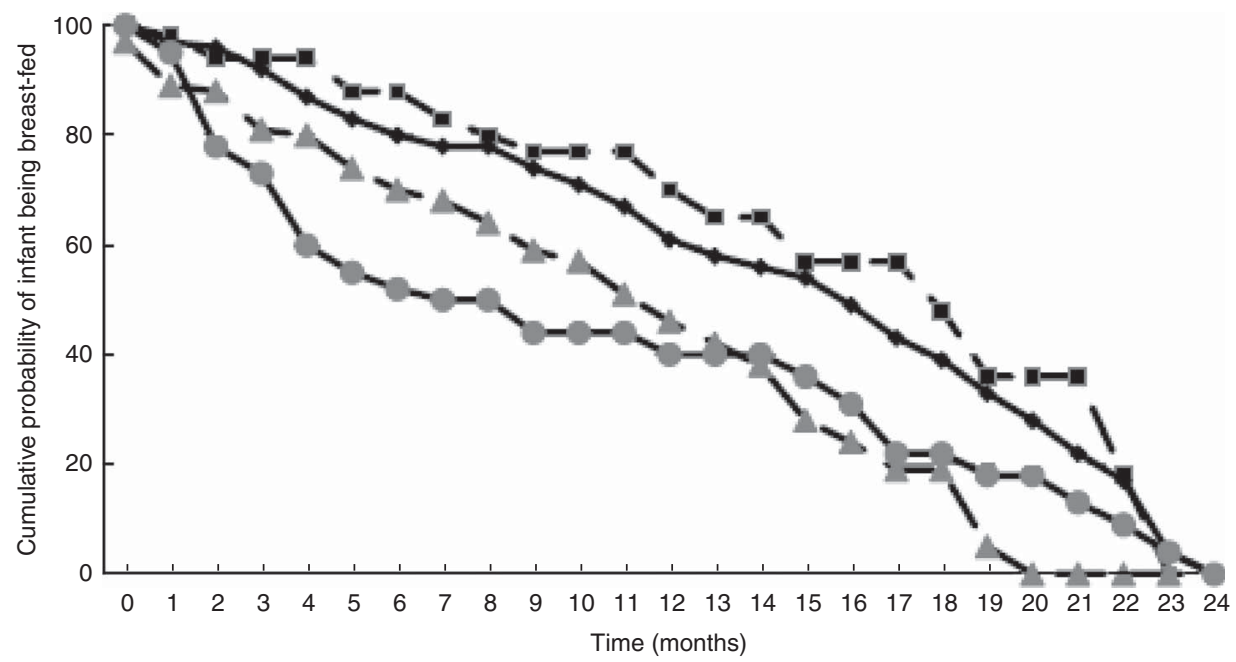

Fig. 3 Breast-feeding practice* of infants according to pre-gestational BMI† (- --, low weight; $-\bullet-$, normal weight; -- , overweight; $-\infty$, obesity), Alagoas, Brazil, 2015. *Wilcoxon's test: $P<0.001$. †Low weight, BMl $<18.5 \mathrm{~kg} / \mathrm{m}^{2}$; normal weight, $B M I=18.5-24.9 \mathrm{~kg} / \mathrm{m}^{2}$; overweight, BMI $=25.0-29.9 \mathrm{~kg} / \mathrm{m}^{2}$; obesity, BMI $\geq 30.0 \mathrm{~kg} / \mathrm{m}^{2}$

few studies on breast-feeding in the state of Alagoas, but there are studies on specific groups. For example, in the study carried out by Ferreira et al. ${ }^{(16)}$, the percentage of children from the semi-arid region under 5 years of age who were breast-fed for more than 1 year was $43.5 \%$. In Maceió, the capital of Alagoas, Assunção et al. ${ }^{(11)}$ found that the BF prevalence in children less than 2 years of age was $38 \cdot 1 \%$.

The median BF duration observed in the current study was also unsatisfactory. Comparing the BF results of the present study with those obtained in the PPAM/Capitals and $\mathrm{DF}$ study ${ }^{(18)}$, the median duration of $\mathrm{BF}(250 \mathrm{~d}$, 8.2 months) was lower than that obtained in Brazil (341.6d, 11.2 months), the Northeast (346.8 d, 11.4 months) and Maceió (331.5 d, 10.9 months). When considering the PNDS $^{(17)}$, the results were similar, as the median duration of
BF was $425.9 \mathrm{~d}$ (14 months). However, EBF practice in the current study demonstrated a slight improvement in median duration to 1.9 months $(60 \mathrm{~d})$ when compared with that in the PPAM/Capitals and DF study ${ }^{(18)}$. This is possibly due to the strategies adopted by public policies to encourage and promote breast-feeding, which are being strengthened in basic care. For example, the Breastfeeding and Feeding Brazil Strategy can explain the change that we observed $^{(19,20)}$. Another possible explanation may be the absence of recent population information, as the information used in the study by Victora et al. was approximately 10 years old, which may be masking the real duration of $\mathrm{BF}$ in the Northeast region of Brazil ${ }^{(4)}$.

The effects of pre-gestational obesity on the duration of breast-feeding practices in the current study are notable since mothers with this status displayed reduced EBF and 
Table 2 Multiple linear regression analysis of factors associated with the duration of exclusive breast-feeding (EBF) in infants, Alagoas, Brazil, 2015

\begin{tabular}{|c|c|c|c|c|c|}
\hline \multirow[b]{2}{*}{ Variables } & \multicolumn{2}{|c|}{ Total ( $n$ 381) } & \multicolumn{3}{|c|}{ EBF duration (d) } \\
\hline & $n$ & $\%$ & Adjusted $\beta$ & $95 \% \mathrm{Cl}$ & $P^{*}$ \\
\hline \multicolumn{6}{|c|}{ Pre-gestational BMI $\left(\mathrm{kg} / \mathrm{m}^{2}\right)$} \\
\hline$<18.5$ & 47 & $12 \cdot 3$ & 1.0 & - & - \\
\hline $18 \cdot 5-24.9$ & 219 & 57.5 & $-32 \cdot 4$ & $-52 \cdot 4,-12 \cdot 3$ & 0.009 \\
\hline $25 \cdot 0-29 \cdot 9$ & 82 & 21.5 & $-28 \cdot 3$ & $-51 \cdot 2,-5 \cdot 4$ & 0.113 \\
\hline$\geq 30 \cdot 0$ & 33 & $8 \cdot 7$ & -51.9 & $-80 \cdot 4,-23 \cdot 4$ & 0.002 \\
\hline \multicolumn{6}{|l|}{ Maternal educationt } \\
\hline Higher education & 33 & 9.3 & 1.0 & - & - \\
\hline High school & 141 & $39 \cdot 6$ & $-14 \cdot 1$ & $-38 \cdot 8,9 \cdot 7$ & 0.115 \\
\hline Primary school & 182 & $51 \cdot 1$ & $-30 \cdot 8$ & $-54.7,-6 \cdot 9$ & 0.035 \\
\hline \multicolumn{6}{|c|}{ Previous breast-feeding experience $\ddagger$} \\
\hline Yes & 189 & $51 \cdot 8$ & 1.0 & - & - \\
\hline No & 73 & $20 \cdot 0$ & $-29 \cdot 0$ & $-45 \cdot 6,-11.5$ & 0.002 \\
\hline Never (primiparous & 103 & $28 \cdot 2$ & -8.6 & $-24 \cdot 7,7 \cdot 4$ & 0.165 \\
\hline \multicolumn{6}{|c|}{ Breast-fed in the first hour§ } \\
\hline Yes & 252 & $66 \cdot 8$ & 1.0 & - & - \\
\hline No & 125 & $33 \cdot 2$ & -9.8 & $-23 \cdot 8,4 \cdot 5$ & 0.080 \\
\hline \multicolumn{6}{|c|}{ Smoking during pregnancy } \\
\hline No & 363 & $95 \cdot 3$ & 1.0 & - & - \\
\hline Yes & 18 & 4.7 & $-34 \cdot 7$ & $-67 \cdot 5,-2 \cdot 0$ & 0.378 \\
\hline \multicolumn{6}{|l|}{ Pacifier use\| } \\
\hline No & 180 & $48 \cdot 1$ & 1.0 & - & - \\
\hline Yes & 194 & 51.9 & $-41 \cdot 4$ & $-54.5,-28.2$ & $<0.001$ \\
\hline
\end{tabular}

*Wilcoxon's test.

†Twenty-five cases without data.

$\ddagger$ Sixteen cases without data.

§Five cases without data.

\|Seven cases without data.

BF behaviour when compared with mothers with other pre-gestational nutritional statuses. Similar findings were observed in surveys conducted by Castillo et al. ${ }^{(5)}$ in a longitudinal section of Pelotas, a city in Southern Brazil, that included 4231 infants. They observed a higher probability of cessation of beast-feeding at 3 months of age among infants of mothers who were obese during the pre-gestational period. Kair and Colaizy ${ }^{(9)}$ observed that overweight and obese women were more likely to discontinue breast-feeding than women who were of normal weight (overweight: $\mathrm{OR}=1.39$; $95 \% \mathrm{CI}, 1 \cdot 16,1 \cdot 68$; obese: $\mathrm{OR}=1.26 ; 95 \% \mathrm{CI}, 1.03,1.54)$. However, Oliveira et al. ${ }^{(21)}$ did not observe a significant association except in one municipality.

Among the possible explanations, the literature reports experimental studies with obese animals that suggest a delay of lactogenesis and less milk synthesis due to histological alterations of the mammary gland characterized by a reduction in the number of ramifications and diameter of the lactating ducts, the deposition of collagen in the lumen of the duct, the abnormal contraction of myoepithelial cells and the possible impairment of alveolar development. Additionally, excess maternal adiposity may promote excessive breast or nipple enlargement, making it difficult for the baby to correctly handle breast-feeding. Obesity may also contribute to higher rates of postpartum depression ${ }^{(8,22)}$.

The number of prenatal visits was not statistically significantly associated with median EBF or BF duration, but the median was relatively higher among mothers who had six or more visits, as recommended by the Ministry of Health. This factor may be due to the positive effect of the intervention of health professionals during prenatal care ${ }^{(21,23-25)}$.

Primiparous mothers, as well as those with previous breast-feeding experience, had longer median lengths of different breast-feeding practices. This may be due to increased support from health and family professionals, as well as positive experiences with breast-feeding, that may contribute to greater self-efficacy and fewer difficulties, concerns and doubts about breast-feeding ${ }^{(26)}$. Some researchers have reported that the duration of $\mathrm{BF}$ was associated with increased parity ${ }^{(26-28)}$. Hass et al. ${ }^{(26)}$ found that previous breast-feeding experience was a predictor of BF continuity at 6 weeks postpartum. Using the third National Health and Nutrition Examination Survey (NHANES) conducted in the USA, Li et al. ${ }^{(28)}$ concluded that multiparous women were less likely to initiate breastfeeding, but were more likely to breast-feed for a longer period.

Infant pacifier use was negatively associated with the duration of EBF. This result may be because when the infant uses a pacifier, the frequency of suckling from the breast decreases, resulting in a decrease in the production of breast milk. The use of pacifiers attracts attention because it causes difficulties in breast-feeding or even demonstrates anxiety and maternal insecurity about the feeding process, which warns us about the need to resolve such issues. Chaves et al. ${ }^{(24)}$ followed a group of 
women for 12 months after childbirth and found a reduction in BF and EBF duration among those who used pacifiers. Silveira and Lamounier ${ }^{(29)}$ carried out a literature review on studies that associated pacifier use with a shorter duration of breast-feeding, and a statistically significant association was found in all the studies.

In the present study, the average duration of different breast-feeding practices was assessed via survival analysis, and interpretation of the results must consider the interviewed mothers' possible memory biases. However, to minimize maternal recall bias regarding dietary information of the children selected for the study, only children up to 2 years of age were included.

The survival analysis technique allows children still being breast-fed at the time of the interview to be considered and the proportion of children who remain breastfed at the end of each month to be known. This technique therefore allows longitudinal 'treatment' of cross-sectional data. However, to perform the multivariate analysis, only children who had stopped breast-feeding were considered since they had an actual median referring to EBF duration.

In addition to the factors mentioned above, multiple linear regression analysis detected a low maternal level of education as a factor associated with a reduced duration of EBF. Mothers with a lower level of schooling may not understand the importance of EBF for children and offer their children water, tea and milk formula before the sixth month of life ${ }^{(21)}$.

The findings show a short duration of EBF among women with pre-gestational obesity and prenatal care may provide an opportunity to guide and encourage mothers to breast-feed their children and to achieve adequate weight gain during pregnancy.

Additionally, the present study may expand and update the situational diagnoses of the health and nutrition of maternal-infant groups in the state of Alagoas to inform government policies and programmes, specifically in relation to high pre-pregnancy BMI and the duration of breast-feeding among children up to 24 months of age.

The construction of other methodological approaches that elucidate individual and social factors to improve the actions taken in prenatal consultations is also recommended.

\section{Acknowledgements}

Acknowledgements: The authors thank the members of the Laboratory of Basic and Applied Nutrition for their help and interest in carrying out the field research. Financial support: This work was supported by the Foundation for Support to Science and Technology of the State of Pernambuco (FACEPE; A.M.S., scholarship) and the National Council of Scientific and Technological Development (CNPq; H.S.F, P.I.C.L., financing of the field research and productivity grants). FACEPE and CNPq had no role in the design, analysis or writing of this article. Conflict of interest: None. Authorship: A.M.S. was responsible for the conception of the study, collected the data, interpreted the data and worked on the writing of the article; H.S.F. carried out the general review; M.L.A. collected the data and carried out the general review; P.I.C.L. worked on designing the study, interpreting the data, guiding the writing of the article and critically reviewing the content of the final version. Ethics of human subject participation: The Human Research Ethics Committee of the Federal University of Alagoas approved the study under protocol number 09093012.0.0000.5013. The families provided informed consent prior to the interviews.

\section{References}

1. Seabra G, Padilha PC, Queiroz JA et al. (2011) Sobrepeso e obesidade pré-gestacionais: prevalência e desfechos associados à gestação (Pre-gestational overweight and obesity: prevalence and outcomes associated with pregnancy). Rev Bras Ginecol Obstet 33, 348-353.

2. Herring SJ, Platek DN, Elliott P et al. (2010) Addressing obesity in pregnancy: what do obstetric providers recommend? I Women's Health (Lanchmt) 19, 65-70.

3. Instituto Brasileiro de Geografia e Estatística (2010) Pesquisa de Orçamentos Familiares 2008-2009: Antropometria e Análise do Estado Nutricional de Crianças, Adolescentes e Adultos no Brasil (Family Budget Survey 2008-2009: Anthropometry and Analysis of the Nutritional Status of Children, Adolescents and Adults in Brazil), 2nd ed. Rio de Janeiro: IBGE.

4. Victora CG, Bahl R, Barros AJ et al. (2016) Breastfeeding in the 21st century: epidemiology, mechanisms, and lifelong effect. Lancet 387, 475-490

5. Castillo H, Santos IS \& Matijasevich A (2016) Maternal prepregnancy BMI, gestational weight gain and breastfeeding. Eur J Clin Nutr 70, 431-436.

6. Hilson JA, Rasmussen KM \& Kjolhede CL (2004) High prepregnant body mass index is associated with poor lactation outcomes among white, rural women independent of psychosocial and demographic correlates. J Hum Lact 20, 18-29.

7. Baker JL, Michaelsen KF, Sorensen TI et al. (2007) High prepregnant body mass index is associated with early termination of full and any breastfeeding in Danish women. Am J Clin Nutr 86, 404-411.

8. Thulier D \& Mercer J (2009) Variables associated with breastfeeding duration. J Obstet Gynecol Neonatal Nurs 38, 259-268.

9. Kair LR \& Colaizy TT (2016) When breast milk alone is not enough: barriers to breastfeeding continuation among overweight and obese mothers. J Hum Lact 32, 250-257.

10. Portela DS, Vieira TO, Matos SM et al. (2015) Maternal obesity, environmental factors, cesarean delivery and breastfeeding as determinants of overweight and obesity in children: results from a cohort. BMC Pregnancy Childbirth 15, 94 .

11. Assunção ML, Ferreira HS, Coutinho SB et al. (2015) Protective effect of breastfeeding against overweight can be detected as early as the second year of life: a study of children from one of the most socially-deprived areas of Brazil. J Health Popul Nutr 33, 85-91.

12. Moreira MA, Cabral PC, Ferreira HS et al. (2012) Overweight and associated factors in children from northeastern Brazil. J Pediatr (Rio J) 88, 347-335. 
13. Instituto de Pesquisa Econômica Aplicada (2016) Desenvolvimento Humano nas Macrorregiões Brasileiras (Human Development in Brazilian Macro Regions). Brasília: PNUD.

14. World Health Organization (2008) Indicators for Assessing Infant and Young Child Feeding Practices. Part 1: Definitions. Conclusions of Consensus Meeting held 6-8 November 2007 in Washington, DC, USA. Geneva: WHO.

15. Institute of Medicine (2009) Nutrition During Lactation. Report of the Subcommittee on Nutrition during Lactation, Committee on Nutritional Status during Pregnancy and Lactation, Food and Nutrition Board. Washington, DC: National Academy Press.

16. Ferreira HS, Vieira EDF, Junior Cabral CR et al. (2010) Aleitamento materno por trinta ou mais dias é fator de proteção contra sobrepeso em pré-escolares da região semiárida de alagoas (Breastfeeding for 30 days or more is a protective factor against overweight in preschool children in the semi-arid region of Alagoas). Rev Assoc Med Bras 56, 74-80.

17. Ministério da Saúde (2009) Pesquisa Nacional de Demografia e Saúde da Criança e da Mulher - PNDS 2006: Dimensões do Processo Reprodutivo e da Saúde da Criança (National Demographic and Child Health Survey - PNDS 2006: Dimensions of the Reproductive Process and Child Health). Brasília: Ministério da Saúde.

18. Ministério da Saúde (2009) II Pesquisa de prevalência de aleitamento materno nas capitais Brasileiras e Distritos Federais (II Research on the Prevalence of Breastfeeding in Brazilian Capitals and Federal Districts). Brasília: Ministério da Saúde.

19. Anversa ETR, Bastos GAN, Nunes LN et al. (2012) Qualidade do processo da assistência pré-natal: unidades básicas de saúde e unidades de Estratégia Saúde da Família em município no Sul do Brasil (Quality of the prenatal care process: basic health units and units of Family Health Strategy in a municipality in the South of Brazil). Cad Saude Publica 28, 789-800.

20. Brandão DS, Venancio SI \& Giugliani ERJ (2015) Association between the Brazilian Breastfeeding Network implementation and breastfeeding indicators. J Pediatr (Rio J) 91, 143-151.

21. Oliveira MGOA, Lira PIC, Filho MB et al. (2013) Fatores associados ao aleitamento materno em dois municípios com baixo índice de desenvolvimento humano no Nordeste do Brasil (Factors associated with breastfeeding in two municipalities with low human development index in Northeast Brazil). Rev Bras Epidemiol 16, 178-189.

22. Kamikawa A, Ichii O, Yamaji D et al. (2009) Diet-induced obesity disrupts ductal development in the mammary glands of nonpregnant mice. Dev Dyn 238, 1092-1099.

23. Vasconcelos MGL, Lira PIC \& Lima MC (2006) Duração e fatores associados ao aleitamento materno em crianças menores de 24 meses de idade no estado de Pernambuco (Duration and factors associated with breastfeeding in children under 24 months of age in the state of Pernambuco). Rev Bras Saude Matern Infant 6, 99-105.

24. Chaves RG, Lamounier JÁ \& César CC (2007) Fatores associados com a duração do aleitamento materno (Factors associated with the duration of breastfeeding). J Pediatr (Rio J) 83, 241-246.

25. Gomes RMT (2013) Perfil epidemiológico de gestantes e qualidade do pré-natal em unidade básica de saúde em Porto Alegre, Rio Grande do Sul, Brasil (Epidemiological profile of pregnant women and prenatal quality in a basic health unit in Porto Alegre, Rio Grande do Sul, Brazil). Rev Bras Med Fam Comun 8, 80-89.

26. Hass DM, Howard CS, Christopher M et al. (2006) Assessment of breastfeeding practices and reasons for success in a military community hospital. J Hum Lact 22, 439-445.

27. Simard I, O'Brien HT, Beaudoin A et al. (2005) Factors influencing the initiation and duration of breastfeeding among low-income women followed by the Canada prenatal nutrition program in 4 regions of Quebec. J Hum Lact 21, 327-337.

28. Li R, Ogden C, Ballew C et al. (2002) Prevalence of exclusive breastfeeding among US infants: the third National Health and Nutrition Examination Survey (Phase II, 19911994). Am J Public Health 92, 1107-1110.

29. Silveira FJF \& Lamounier JA (2004) Prevalência do aleitamento materno e praticas de alimentação complementar em crianças com até 24 meses de idade da região do Alto Jequitinhonha, Minas Gerais (Prevalence of breastfeeding and complementary feeding practices in children up to 24 months of age in Alto Jequitinhonha, Minas Gerais). Rev Nutr 17, 437-447. 